\title{
USO DE MAPEAMENTO GEOTÉCNICO PARA CARACTERIZAÇ̃̃O DAS ESTRADAS VICINAIS DE JAIIBA, FEIRA DE SANTANA- BA.
}

\author{
$\underline{\text { Nadine de Jesus Santos }}{ }^{1}$; Gracinete Bastos de Souza $^{2}$; Igor Ferreira de Almeida ${ }^{3}$ e \\ Juliele Nascimento Jesus ${ }^{4}$ \\ 1. Bolsista PROBIC/UEFS, Graduando em Engenharia Civil, Universidade Estadual de Feira de Santana, e-mail: \\ nadinesanttos@gmail.com \\ 2. Orientador, Departamento de Exatas, Universidade Estadual de Feira de Santana, e-mail: \\ graciesouza@gmail.com \\ 3. Participante do projeto Integração de Dados dos Aspectos do Meio Físico do Município de Feira de Santana, BA, \\ Departamento de Tecnologia, Universidade Estadual de Feira de Santana, e-mail: \\ Igor.almeidaig@gmail.com \\ 4. Participante do projeto de Dados dos Aspectos do Meio Físico do Município de Feira de Santana, BA, \\ Departamento de Tecnologia, Universidade Estadual de Feira de Santana, e-mail: \\ njjuliele@gmail.com
}

PALAVRAS-CHAVE: Mapeamento geotécnico; estradas; Jaíba.

\section{INTRODUÇÃO}

As estradas vicinais são vias não pavimentadas, de uma só pista com baixo volume de tráfego diário, mais conhecidas como estrada de chão. Estas estradas são desprovidas de qualquer tipo de tratamento superficial, betuminoso ou de cimento, tendo, geralmente, sua camada superficial constituída por solo local, às vezes em mistura com agregado granular (ODA et al., 2001 apud JÚNIOR, H. H). No Brasil há uma predominância de estradas não pavimentadas, segundo o Departamento Nacional de Infraestrutura de Transportes (DNIT).

As estradas vicinais possuem grande importância para a área urbana e rural do Brasil, as mesmas são de grande relevância tanto para a mobilidade como também econômica e ambiental. Esses tipos de estradas são as principais formas de locomoção para os moradores das áreas rurais. Esse tipo de estrada é a principal via de ligação entre o povoado e a sede do distrito, é exclusivamente a única forma de acesso para estudar, trabalhar, ir ao médico e transportar produtos agrícolas dos pequenos produtores.

A má condição dessas vias traz transtornos para os usuários e para os moradores da localidade, pois às condições das mesmas, afetam o dia a dia das pessoas que dependem da estrada e ainda impossibilitam as melhorias necessárias para os povoados.

O estudo sobre o estado de conservação das estradas vicinais do distrito de Jaíba se faz necessário, pois busca identificar os principais problemas físicos ocasionados pela falta de manutenção adequada.

\section{METODOLOGIA}

Este trabalho foi desenvolvido por meio dos seguintes passos: revisão bibliográfica com o intuito de obter o embasamento necessário sobre os temas em estudo, tais como mapeamento geotécnico, geologia de engenharia, estradas vicinais, SIGs, geotecnia e sobre as informações do distrito de Jaíba. Para a elaboração dos mapas, espacialização e armazenamento dos dados foi utilizado o SPRING 5.2, software livre desenvolvido pelo INPE (Instituto Nacional de pesquisas Espaciais).

Além disso, fez-se um trabalho de campo para reconhecimento da estrada e das informações gerais das características físicas do distrito, no campo foram observados aspectos como os principais problemas que existentes na estrada (erosão, vegetação, 
drenagens, largura, entre outros), tipos de materiais inconsolidados, vegetação, uso e ocupação do solo e também a urbanização. Foram obtidas coordenadas de posicionamento geográfico com o GPS; algumas áreas foram fotografadas, registrando as informações físicas da estrada; foi necessário em campo o uso de trenas, indispensável para a obtenção das larguras da estrada. Todos os equipamentos acima tiveram como principal objetivo detalhar os principais trechos das estradas, fazendo observações importantes para assim caracterizá-la e descrevê-la da melhor forma possível, apontando os principais problemas existentes nessas vias, deste modo realizar um diagnóstico da situação dessas estradas.

\section{RESULTADOS E DISCUSSÃO}

A estrada estudada foi à estrada de São Roque, conhecida por alguns moradores como a estrada velha de Jaíba. O trecho percorrido foi de aproximadamente 7,4 Km de extensão, não houve dificuldades para fazer o percurso da estrada, logo nota-se que a pista de rolamento apresenta características técnicas razoáveis; porém ressalta-se que o trabalho de campo foi realizado numa época de seca, o que pode influenciar nas observações, nos problemas relatados, nas análises e nos resultados obtidos.

Largura da estrada

A estrada apresenta uma largura que varia entre 3,40 á 8,90 metros, apresentando assim alguns lugares muito estreito, permitindo a passagem de um veículo por vez, e outros com largura suficiente para passagem de mais de um veículo (Figura $1-\mathrm{A})$.

\section{Drenagem Inadequada}

Os dispositivos de drenagem que a estrada de São Roque possui, são rústicos, feito pelos moradores da região, geralmente são valetas criadas de modo que ligam a estrada ao terreno as margens da mesma, para retirada da água acumulada (Figura 1-C).

Porém, além de rústicos, os dispositivos encontrados na estrada apresentam falta de manutenção, comprometendo o funcionamento dos mesmos; observa-se ainda que os dispositivos estão sendo assoreados, fechando assim a passagem da água, isso acontece devido os materiais que á enxurrada carrega, e com o passar do tempo acaba fechando a passagem da água.

\section{Erosões}

Foi observado que a estrada estudada apresentou em alguns pontos erosões (Figura 1-B) o que acaba danificando os veículos que passam por essa região, além disso, interfere no tempo de trajeto da estrada prejudicando assim moradores e condutores dos veículos no dia a dia.

\section{Corrugações}

As corrugações vistas na estrada estudadas são suaves, porém mesmo sendo suaves, causam causando trepidação nos veículos e consequentemente desconforto aos usuários. Observar (Figura 1-A).

Afloramento de rochas na estrada

Pelas características da estrada estudada, notou-se que a principal forma de manutenção da mesma é a patrolagem, popularmente conhecida como a raspagem da estrada, essa técnica de manutenção, quando utilizada constantemente, facilita a presença de alguns defeitos na estrada, entre eles o afloramento de rocha. Foram observados vários pontos da estrada que apresentavam amostras de rochas (Figura 1-A), dificultando assim o tráfego. 


\section{Excessos de poeira}

A estrada analisada apresenta alguns trechos com grande quantidade de material fino (Figura 1-E), apresentando assim excesso de poeira, porém o nível de severidade do problema é baixo. A estrada apresenta uma simples camada suspensa de poeira, trazendo desconforto ao usuário.

Segregação de Agregados

A estrada de São Roque apresenta alguns trechos com (Figura 1-A) segregação de agregados, porém em quantidade que não oferece perigo ao tráfego, pois os agregados têm dimensões pequenas e estão espalhados na estrada, não apresentando assim acúmulo para tornar a estrada escorregadia. No entanto, pode obstrui os dispositivos de drenagem da estrada e estragar a pintura dos veículos.

\section{Falta de sinalização}

A estrada de São Roque não apresentou nenhuma sinalização em grande parte de sua extensão, dificultando assim o trânsito e aumentando o nível de acidentes, além disso, notou-se muita vegetação na beira da estrada(Figura 1-D), atrapalhando assim a visibilidade do motorista e agravando a situação de risco.

Estrada encaixada no terreno

$\mathrm{Na}$ estrada em estudo foi observado que grande parte da mesma está encaixada no terreno(Figura 1-E), evidenciando uma manutenção inadequada, desnível variou em toda a estrada, apresentando locais em que não ocorria tal situação.

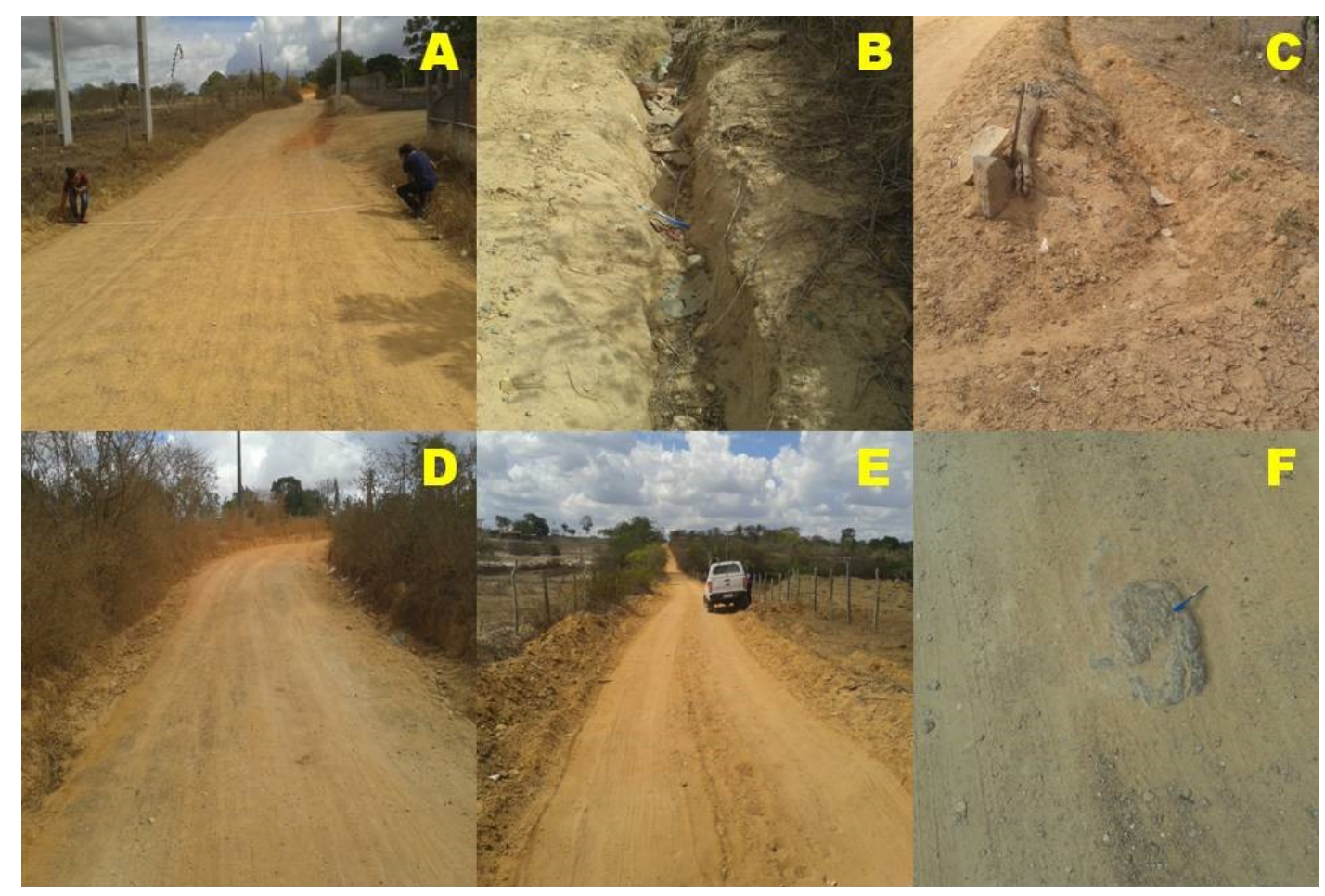

Figura 1- Principais problemas encontrados na estrada de São Roque. Em (A) largura da estrada e corrugações suaves. Em (B) erosão profunda . (C) drenagem inadequada. (D) apresenta vegetação na estrada e segregação de agregados. (E) excesso de poeira e estrada encaixada no terreno. (F) afloramento de rocha. 
O SPRING foi o sistema de informação geográfica (SIG) utilizado no trabalho, nele foi criado o mapa que contém informações do distrito, o mapa apresenta o limite do distrito, os pontos marcados no GPS no trabalho de campo e a disposição das estradas de Jaíba.

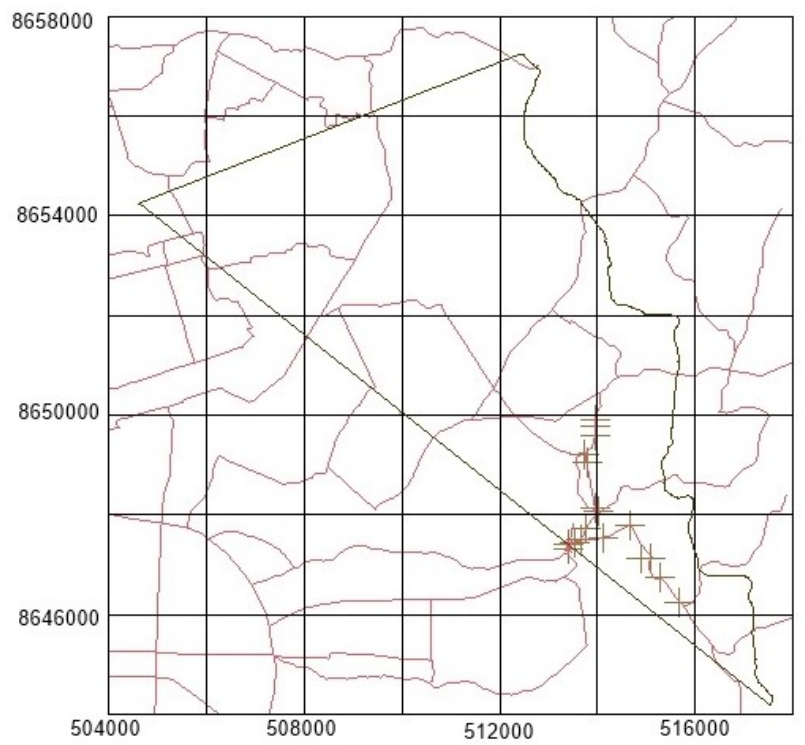

$$
\begin{aligned}
& \text { Legenda } \\
& \text { Pontos } \\
& \text { Estradas } \\
& \text { Limite }
\end{aligned}
$$

Figura 2- Mapa de Jaíba feito no Spring contendo limite, estradas, pontos e grade

\section{CONSIDERAÇÕES FINAIS}

A pesquisa foi de suma importância para ratificar a situação atual das Estradas Vicinais brasileiras, foi estudada a estrada de Jaíba, mais especificamente a estrada de São Roque que liga o distrito ao povoado de São Roque, a cidade de Coração de Maria e ainda aos Bairros do Sim e Santo Antonio que estão em expansão imobiliária, atribuindo assim maior importância a essa estrada.

Com base no que foi analisado durante o trabalho teórico e o trabalho de campo constatou-se que a estrada está em situação técnica razoável. A estrada apresenta alguns trechos sem buracos, com poeira moderada e largura suficiente para trafegar dois veículos; apresentando nível igual ou próximo ao terreno, facilitando assim a drenagem. Poucos trechos apresentam afloramentos de rochas, corrugações, poeira excessiva, largura inadequada e segregação de agregados. Observou-se que a utilização da patrolagem sistemática proporcionou e/ou agravou alguns problemas para a estrada, além disso, a falta de obras de prevenção tornou o sistema de drenagem em alguns locais ineficiente, trazendo mais problemas a essa via.

\section{REFERENCIAS}

BAESSO, D. P. GONÇALVES, F. L. R. Estradas rurais: técnicas adequadas de manutenção. Florianópolis: DER, 2003. 204 p. Versão digital. BASTOS, G. (1996). Estudo com Sistema de Informação Geográfica para o Mapeamento Geotécnico do Município de Feira de Santana - BA. Dissertação de Mestrado, Publicação GDM - 035A/96, Departamento de Engenharia Civil, Universidade de Brasília, Brasília, DF, 114.

JÚNIOR, H.H; FERREIRA, O.M. Processos Erosivos e Perda de Solo em Estradas

Vicinais.

Disponível

em: $<$ http://www.pucgoias.edu.br/ucg/prope/cpgss/ArquivosUpload/36/file/Continua/PROC ESSOS\%20EROSIVOS\%20E\%20PERDA\%20DE\%20SOLO \%20EM\%20ESTRADAS \%20VICINAIS.pdf $>$ Acesso em: 12 de agosto de 2016 